\title{
Nutritional indices in the gypsy moth (Lymantria dispar (L.)) under field conditions and host switching situations
}

Received: 8 February 1993 / Accepted: 9 November 1993

\begin{abstract}
A large proportion of gypsy moths (Lymantria dispar (L.)) are likely to experience multiple species diets in the field due to natural wandering and host switching which occurs with these insects. Nutritional indices in fourth and fifth instar gypsy moth larvae were studied in the field for insects that were switched to a second host species when they were fourth instars. The tree species used as hosts were northern pin oak ( $Q u e r-$ cus ellipsoidalis E. J. Hill), white oak ( $Q$. alba L.), bigtooth aspen (Populus grandidentata Michx.), and trembling aspen (P. tremuloides Michx.). Conclusions of this study include: 1) Insects which fed before the host switch on northern pin oak performed better after the host switch than did insects with other types of early dietary experience. While the northern pin oak-started insects had very low relative food consumption rates on their second host species immediately after the switch, one instar later they had the highest ranked consumption rates. During both instars they had the second highest efficiencies of converting ingested and digested food to body mass. High food consumption rates and relatively high efficiency of food conversion helped these insects to obtain the highest ranked mean relative growth rates in the fifth instar compared to the relative growth rates obtained by insects from any of the other first host species. 2) Among the four host species examined, a second host of trembling aspen was most advantageous for the insects. Feeding on this species after the switch led to higher larval weights and higher relative growth rates for insects than did any of the other second host species. The insects on trembling aspen attained excellent growth despite only mediocre to low food conversion efficiencies. The low efficiencies were offset by
\end{abstract}

J. L. Stoyenoff $(\bowtie) \cdot$ J. A. Witter

School of Natural Resources and Environment,

University of Michigan,

Ann Arbor, MI 48109-1115, USA

M. E. Montgomery

Northeastern Forest Experiment Station, USDA Forest Service, Hamden, CT 06514, USA high relative food consumption rates. 3) Low food consumption rates often tend to be paired with high efficiency of conversion and vice versa. 4) There is no discernable tendency for the first plant species eaten to cause long-term inductions which affect the ability of gypsy moths to utilize subsequent host plants. Insects did not tend to consume more, grow faster, or be more efficient if their second host plant was either the same as their rearing plant or congeneric to it. Methods are delineated which allow values of nutritional indices to be obtained for insects on intact host plants under field conditions. These methods are useful for the purpose of answering questions about the relative effects that different diet treatments have on insect response.

Key words Nutritional indices $\cdot$ Host switching Gypsy moth $\cdot$ Food utilization

\section{Introduction}

The gypsy moth is a generalist folivore which at the population level will feed on over 300 species of woody plants (Leonard 1981). Polyphagous feeding habits are evident at the level of individual larvae as well. This is evidenced by the young caterpillars' high interplant mobility in the spring as they disperse on the wind and select host plants (Capinera and Barbosa 1976; Lance and Barbosa 1981; Witter and Stoyenoff submitted) and by frequent host switching of the older larvae, especially in relatively dense populations (Doane and Leonard 1975; Lance and Barbosa 1982; Liebhold et al. 1986). Each day as many as $30 \%$ of gypsy moth larvae may move between host trees in high density gypsy moth populations (Liebhold et al. 1986). While some of this movement will take place between conspecific trees, much of the movement in mixed stands may occur between trees of different species (Barbosa 1978a; Mauffette and Lechowicz 1984). Therefore, many gypsy moths may experience multiple hosts in their diets. 
The costs and benefits to organisms that follow polyphagous feeding strategies relative to those that are more highly specialized have been debated (Krieger et al. 1971; Price 1975; Rhoades and Cates 1976; Feeny 1976; Wasserman 1979; Scriber and Feeny 1979; Scriber 1979; Cates 1980; Bernays and Graham 1988). Some have suggested that polyphagous feeders may suffer high costs to maintain and activate detoxification systems, such as mixed function oxidase systems, that are needed to successfully deal with a wide range of plant defensive compounds (Krieger et al. 1971; Brattsten 1979; Scriber 1981). Others, however, have felt that level of cost is more sharply differentiated between phytophagous tree feeders and phytophagous forb feeders, rather than between organisms following polyphagous versus monophagous strategies (Wasserman 1979; Scriber and Feeny 1979). There has been evidence, both for insect species that are polyphagous at the level of the individual and for insect species that are more specialized at the level of the individual, that switching between different diet items may lead to a variety of negative effects such as lowered consumption rates, reduced growth rates, decreased efficiency in converting food to body tissue, lowered pupal weights, and increased mortality (Jermy et al. 1968; Yamamoto 1974; Hanson 1976, 1983; Schoonhoven and Meerman 1978; Barbosa et al. 1979; Scriber 1979, 1981, 1982; Grabstein and Scriber 1982; Karowe 1989). Such negative effects may occur because some insects can become behaviorally and physiologically adjusted to their first host plant so that this early feeding experience affects acceptance for, and physiological utilization of, later hosts (Jermy et al. 1968; Yamamoto 1974; Ishaaya and Swirski 1976; Hanson 1976; Greenblatt et al. 1978; Schoonhoven and Meerman 1978; Barbosa et al. 1979; Scriber 1979, 1981, 1982; Brattsten et al. 1980; Yu 1982; Grabstein and Scriber 1982; Ahmad 1983; Redfearn and Pimm 1988; Karowe 1989).

For the gypsy moth, both laboratory and field studies have indicated that switching between favorable host plants does not in general cause great harm to these insects and, indeed, if appropriate diet switches are made, larval performance may benefit greatly from a diet involving a switch as compared to a continued diet of their first host species alone (Barbosa 1978b; Barbosa et al. 1986; Roden and Surgeoner 1991; Stoyenoff et al. 1994). Reasons for high performance on certain host sequences have been speculated upon but are somewhat unclear. Work on food consumption and efficiency of food utilization by gypsy moths in host switching situations has been entirely lacking.

Calculation of nutritional indices using gravimetric methods developed by Waldbauer (1968) and others has been a very important tool over the past 25 years in helping to elucidate quantitative changes in consumption and assimilation for a number of insects on a variety of diet regimes. However, such work has continued to be performed almost exclusively in the laboratory with little effort directed at developing and implement- ing techniques which would allow examination of insect dietary utilization in the field. This is surprising since insect responses and the research questions that can be addressed related to insect feeding may be somewhat different in the field and in the lab. Waldbauer himself indicated the utility and importance of developing further methods which would ultimately allow food utilization to be measured for insects on intact host plants in field situations (Waldbauer 1968). Here we present the results of a field study of host utilization in the gypsy moth. The purposes of our research were to: 1) compare food utilization indices for gypsy moths on various host species after a switch between two favorable diet items has occurred, 2) determine how these indices are altered after insects have an additional instar of experience feeding on their new host plant, 3) determine whether values of indices tend to be higher when insects continue feeding on the same species or switch to a congeneric species than when insects switch between non-congeneric host plants, and 4) develop methods that allow comparisions of food utilization indices for insects maintained under field conditions on intact host plants.

\section{Materials and methods}

Host plant species and study sites

Experiments were performed in 1991 at a previously cut-over site in eastern Crawford County (T26N, R1W, S14 and 23), Michigan. Understory-sized regrowth trees of northern pin oak (Quercus ellipsoidalis E. J. Hill), white oak (Q. alba L.), bigtooth aspen (Populus grandidentata Michx.), and trembling aspen ( $P$. tremuloides Michx.) were used as hosts. These species are found commonly throughout the Lake States region and are important, preferred food sources for the gypsy moth. They are frequently found in mixed stands in Michigan and represent a realistic set of tree species that gypsy moth larvae may switch between.

Insects

\section{Rearing}

Gypsy moth egg masses were collected from the leading edge of an expanding infestation in central Michigan. Egg masses were surface sterilized and stored at $5^{\circ} \mathrm{C}$ (ODell et al. 1985). Hatch took place in a $25^{\circ} \mathrm{C}$ incubator and was timed to coincide with natural gypsy moth eclosion in the field (May 20, 1991).

Neonate larvae collected from the lab-hatched egg masses were placed for rearing onto 15 trees of each of the four host species. The weight of a newly hatched larva averaged $0.0006 \mathrm{~g}$. Larvae were contained on the trees using fine mesh sleeve bags. Such bags have no effect on phenolic chemistry of enclosed oak leaves (Rossiter et al. 1988). Each rearing tree supported six sleeve bags and each bag held 15 larvae with an adequate food supply for several weeks. A total pool of 1350 larvae were placed for rearing on each host species. These larvae were used as the pool of insects to draw from for field experiments and for accompanying wet-dry ratios and laboratory work.

The larvae fed on their rearing trees for the first three instars (May 20 to June 7, 1991). During this time insects were not disturbed except to provide them with additional food if needed. This was done by inserting more leaf material from the same branch into the mouth of the sleeve bag. When the majority of the insects were molting to the fourth instar, bags were removed from five to 
Table 1 All possible two-host diet combinations with four tree species $^{\mathrm{a}}$

\begin{tabular}{lllll}
\hline \multirow{2}{*}{ First host } & \multicolumn{4}{l}{ Second host } \\
\cline { 2 - 5 } & NP & WO & TA & BT \\
\hline NP & NP-NP & NP-WO & NP-TA & NP-BT \\
WO & WO-NP & WO-WO & WO-TA & WO-BT \\
TA & TA-NP & TA-WO & TA-TA & TA-BT \\
BT & BT-NP & BT-WO & BT-TA & BT-BT
\end{tabular}

${ }^{\mathrm{a}} N P=$ northern pin oak; $W O=$ white oak; $T A=$ trembling aspen; $B T=$ bigtooth aspen

seven trees of each host species, and instars and weights were determined individually for each insect from these bags. This information was used to build distribution graphs of weights for the approximately 400 to 600 insects which we weighed from each of the four host species. Because gypsy moth molting is not highly synchronous, some individuals that were in the bags were still third instars at, the time that the bags were removed from the trees. These insects were discarded before weighing took place, as were insects which were obviously older fourth instars (more than a few days old). Only insects which were newly molted fourth instars or appeared to be very young fourth instars were weighed and used in subsequent experiments. While there is some difference in size of male and female gypsy moth larvae in the later instars, we did not separate insects in these experiments by sex due to time constraints. Because larvae were randomly assigned to diet treatments and because sample sizes used for the experiments were large, imbalances in sex ratios likely were minimal and not significant in affecting major conclusions of the study.

At the time that insects were assigned for the field experiment, randomly selected aliquots of 17 to 26 larvae also were taken from each host species to calculate an initial wet-to-dry weight ratio for insects on the different hosts. These larvae represented a mixture of inects that were newly molted to the fourth instar and insects that were young fourth instars for each of the host species.

It was not possible to use all newly molted larvae in the experiments due to the large number of larvae needed (more than 1100 larvae) and the fact that a fairly small percentage of larvae are newly molted at any one time. It was necessary to collect insects from the bags on only a single day rather than over a period of several days so that the outdoor feeding trial would be performed on identical days for all treatments, ensuring that all insects would be exposed to the same weather conditions during the course of the experiment. Using an experimental time period that falls within a stadium and does not start and end with a molt also has been done by others (Evans 1939; Chauvin 1946). This method is disadvantageous because residual food may be retained in the gut at the beginning or end of the experiment, causing an error in determining the weight of the insect and the weight of its frass (Waldbauer 1968). However, any error occurring in the present experiment due to gut retention of food in larvae which are not newly molted should be evenly distributed across all treatment types and across field trials, laboratory work, and wet-to-dry weight ratio determinations. Since all segments of the experiment experienced this, we feel that it is valid to make comparisons of results obtained in our experiments among the various treatment types studied.

\section{Fourth instar trial}

Once the experimental larvae had been selected and weighed, they were placed onto new host plants in the field (June 8 and 9,1991). Placements were made so that all possible two-host diets would be examined in the study (Table 1). Each possible diet sequence was represented by 35 to 49 larvae from the appropriate first host species. Larvae to be used in the experiment from each first host species were randomly assigned to the various second host spe- cies. Larvae were put individually into separate small sleeve bags ( $28 \mathrm{~cm}$ long by $13 \mathrm{~cm}$ wide) with identification numbers, and the groups of bags were then placed onto one to two trees of the appropriate second host species. Each sleeve bag contained numerous leaves of the host plant which gave larvae the opportunity for ample choice among individual leaves as they were foraging. Use of these small sleeve bags containing individual larvae allowed us to follow each larva separately in the subsequent measurements and allowed easy collection of frass produced by an individual insect. Because the bags were made of extremely fine tent netting which had been manufactured to prevent penetration of no-see-ums or biting midges (Diptera: Ceratopogonidae), quantitative collection of even small frass particles was possible without loss. Additionally, little frass pellet breakage was observed.

At the same time that experimental insects were being placed onto their new trees in small sleeve bags, large sleeve bags remaining on each rearing species (bags not used for selection of experimental larvae) were likewise moved to appropriate second host species so that all possible diet combinations were represented with large sleeve bags. These larvae were exposed to the same diet sequences as the experimental larvae so that they could be used for laboratory work and ratio determinations associated with the field experiments and so that they could be used as necessary to increase sample sizes for the later experiments by using insects which had correct diet histories.

The first feeding trial began when the experimental insects had been weighed and placed on their new host plants as early fourth instars. This trial lasted for a period of 3 to $3.5 \mathrm{~d}$. We wished to conduct the feeding trial for a period of three days early in the instar to ensure that insects would not molt during the course of the trial and to minimize the chance of rainstorms occurring while the trial was taking place. If rainstorms had occurred, resulting water potentially could have leached frass produced in our unsheltered cages in the field, thus altering frass weights, or the addition of water to the soil could have changed foliar water levels significantly. Due to length of time required to handle insects and sleeve bags for the experiment, however, half of the experimental insects were on the trees for an additional half day period before they could be removed. Thus, calculations for these insects were based on $3.5 \mathrm{~d}$ rather than $3 \mathrm{~d}$. No rain occurred during the experiment. At the end of the trial, insects were weighed and the frass produced by each during this period was collected, dried, and weighed. Most of the insects were then returned to the trees and fed there until the majority were molting to the fifth instar, when the second field trial would take place. Five insects from each diet combination were sacrificed, however, to provide an estimate of the dry-to-wet weight ratio for insects on the various diets at the end of this experiment; these aliquots were supplemented by additional larvae ( 9 to 19 additional per diet sequence, depending upon availability) drawn from large bags which had been treated with appropriate diet exposure to increase the sample sizes for calculating ratios.

\section{Fifth instar trial}

When the majority of the experimental insects were molting to fifth instars, the small sleeve bags were removed from the trees and the insects were weighed. Any insects which had not yet molted to the fifth instar or which had extremely atypical weights (e.g., very small due to lack of feeding caused by parasitization or infection with virus) were discarded. Because of this cull and because of natural mortality which took place between the beginning of the fourth instar trial and the beginning of the fifth instar trial, sample sizes had fallen below those desired. Therefore, insects from large sleeve bags which had been treated with the appropriate diet switches since the fourth instar were weighed and typical individuals from these bags which were newly molted fifth instars or which had recently molted to the fifth instar were randomly selected for addition to the groups of experimental insects. Individuals from the large sleeve bags also were selected for each diet type to 
provide an initial dry-to-wet weight ratio for larvae in the fifth instar experiment. Only experimental insects and insects from large sleeve bags that were newly molted fifth instars or very young fifth instars were used for the fifth instar trial.

The fifth instar feeding trial commenced in the field on June 18 and 19,1991, and was concluded after $3 \mathrm{~d}$ of feeding in the early part of the fifth stadium. Each possible diet sequence was represented by 27 to 51 weighed experimental larvae which had been exposed to their second host species since the early fourth instar. At the end of the feeding trial, insects were weighed and frass from the $3 \mathrm{~d}$ period was collected. Once again, no rain occurred during the experimental period. A final dry-to-wet weight ratio for laryae from each diet sequence was calculated based on aliquots of 5 to 18 larvae drawn from large sleeve bags that had received the appropriate diet treatments.

\section{Laboratory work}

At the same time that the field experiments were being carried out on fourth and fifth instar larvae, accompanying lab work was performed to allow us to relate amounts of frass produced by the field insects to amounts of leaf material that they were consuming. For both time periods, insects of the appropriate age were drawn from large sleeve bags which had been exposed to appropriate diet sequences, and approximately 20 insects from each diet sequence were fed at field temperatures on known quantities of whole leaves from the tree which was supporting the small sleeve bags for that diet sequence. The feeding was done at the fourth instar by placing small groups of larvae from a particular diet sequence into large petri dishes sealed with Parafilm ${ }^{\oplus}$ and at the fifth instar by placing the entire group of larvae from a given diet sequence into a large zipper-sealed plastic bag with adequate air space. Three days later, the insects were removed, and the dry weights of remaining leaf pieces and of frass were determined for the group of larvae representing each diet sequence. Dry-to-wet weight ratios of the leaves of each experimental tree were determined concomitantly with these feeding trials. These pieces of information allowed us to calculate ratios of the amount of food eaten to the amount of frass produced for insects on the various diet types. These ratios for each diet type were used as a conversion factor to determine amounts of food that were eaten by experimental insects in the field based on amounts of frass that they produced ([frass produced by experimental insect caged on tree] $\times$ [lab ratio of amount of food eaten to amount of frass produced]= amount of food eaten by experimental insect caged on tree). Correlations between frass weights and food consumption have been found to be highly significant for a variety of lepidopterous larvae and unaffected by factors such as developmental stage, environmental temperature, or food quality (Mathavan and Pandian 1974). Use of lab determined frass-to-food ratios to obtain food consumption information for animals in the field from weight of fecal matter produced has been successfully implemented for harvestmen (Arthropoda: Phalangida) as well (Phillipson 1960).

\section{Analyses}

Information generated by the fourth and fifth instar studies was used to calculate Waldbauer nutritional indices (Waldbauer 1968). Indices calculated are shown in Table 2. Growth rates and consumption rates were calculated relative to the fresh weights of the insects at the beginning of an experimental period rather than relative to the mean animal weights during the experimental periods. This was done to avoid inaccuracies and confounding effects which occur in these indices when mean animal weights are used and experiments are of short duration, such as within a single instar (Farrar et al. 1989).

Consumption rates in these experiments were calculated on both a dry food basis (using dry weight of food eaten and fresh weight of insect) and a wet food basis (using fresh weight of food eaten and fresh weight of insect). Consumption was calculated in
Table 2 Nutritional indices

Relative growth rate

$\mathrm{RGR}=$ (insect wet wt. gain)/(insect wet wt. at beginning of trial)(time $\left.{ }^{\mathrm{a}}\right)$

Relative consumption rate-dry food basis $\mathrm{RCR}=$ (dry wt. food eaten) $/$ (insect wet wt. at beginning of trial)(time $\left.{ }^{\mathrm{a}}\right)$

Relative consumption rate-wet food basis $\mathrm{RCR}=$ (wet wt. food eaten)/(insect wet wt. at beginning of trial)(time $\left.{ }^{\mathrm{a}}\right)$

Efficiency of conversion of ingested food (gross efficiency) $\mathrm{ECI}=[($ insect dry wt. gain $) /($ dry wt. food eaten $)] \times 100$

Efficiency of conversion of digested food (net efficiency) $\mathrm{ECD}=[($ insect dry wt. gain $) /($ dry wt. food eaten dry wt. frass) $] \times 100$

a time $=3$ or $3.5 \mathrm{~d}$, as appropriate for the trial and removal time of a particular insect

both of these ways to allow an examination of both physiological and behavioral responses to the various food types. Waldbauer (1968) states that consumption calculated from the dry weight of food is a measure of the rate at which nutrients are entering the insect's digestive system, whereas consumption calculated from the wet weight of food is a measure of insects' behavioral response to the food. Since different types of food contain different percentages of dry matter, the rank order of food consumption on dry and wet weight bases can be different, with insects possibly consuming a certain host the most on a wet weight basis but taking in nutrients more rapidly on another host even though they are eating less of that other host on a wet weight basis.

Statistical analyses were performed with the General Linear Models (GLM) procedure in SAS (SAS 1985). Data from the experiments were analyzed separately for the fourth and fifth instar trials. For each instar a two-factor crossed ANOVA with interaction was employed (factor $\mathrm{A}=$ first diet species larvae were treated with; factor $B=$ second species larvae were fed). Since larvae were followed individually in separate sleeve bags, the sampling unit for both experiments was the individual.

Tree was not included as a separate factor in this study. Experimental insects from the four first hosts were chosen from a large pool of insects that came from different individual trees, but the insects were selected in a blind manner from the group based on meeting developmental standards. It was not known which particular tree each individual insect came from during this selection process; only the species of the first host tree was known. After the host switch, all insects from each diet sequence were placed together onto only a single tree of the appropriate second host species except in the case of three diet sequences. These three sequences were represented by two trees each after the host switch. However, ANOVA tests in each case found no significant differences in insect weights or growth rates at either instar between the insects on the two different trees in each pair. Therefore, data from insects on both trees were pooled for final analysis in all three cases.

Assumptions of all models were tested using plots of the residuals versus the predicted values, normal probability plots, stemand-leaf plots, and skewness and kurtosis coefficients. Square root and $\log$ transformations were performed on the data before analysis to aid in more closely meeting assumptions of normality and homogeneity. These transformations aided greatly in meeting model assumptions, but data for many variables were still somewhat kurtotic after transformation. While there was, therefore, some departure from ideal model conditions, differences in group means were generally large so test results were less affected by the departure and readily reflect differences seen in the data upon inspection. In addition, the ANOVA models used are relatively robust to moderate departures from assumptions. 
Scheffe's multiple comparison procedure was used to further evaluate the data. This procedure was employed for tests of all pairwise comparisons because its relatively low power reduces the risk of Type I error. An experimentwise $\alpha$ of 0.05 was used.

\section{Results}

Larval weights

After three instars of feeding on an initial host plant, insects from northern pin oak had the highest ranked average weight $(0.116 \pm 0.002 \mathrm{~g}$ [mean \pm standard error]), although their weight was not significantly greater than that of insects from either white oak $(0.111 \pm 0.002$ g) or bigtooth aspen $(0.111 \pm 0.004 \mathrm{~g})$. Trembling aspenfed larvae had significantly lower average weight than larvae from all other first host species $(0.095 \pm 0.002 \mathrm{~g})$ (ANOVA $p=0.0001$ for first host).

After 3 to 3.5 days of feeding on a second host species, no difference could be detected with Scheffé's
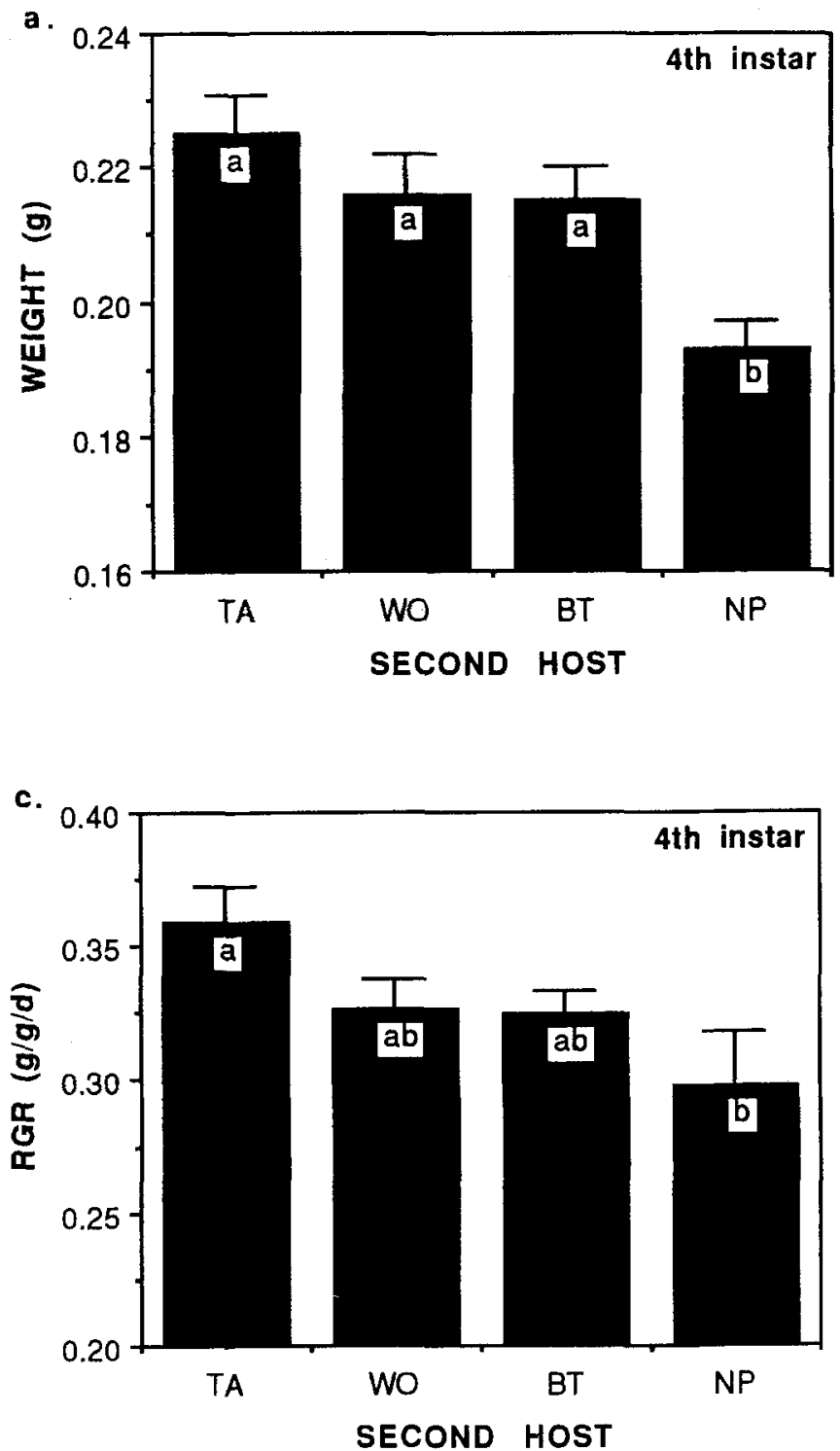

procedure among the groups of insects that had come from the various first host species (trembling aspen $=$ $0.221 \pm 0.006 \mathrm{~g}$; white oak $=0.219 \pm 0.004 \mathrm{~g}$; northern pin oak $=0.205 \pm 0.005 \mathrm{~g}$; bigtooth aspen $=$ $0.204 \pm 0.007 \mathrm{~g}$; ANOVA $p=0.0279$ for first host), but the type of second host species consumed did significantly affect weights even after this short exposure time (ANOVA $p=0.0001$ for second host) (Fig. 1a). Insects moved onto a second host of northern pin oak from all first host species had significantly lower weights on average than did larvae feeding on any of the other second host species. Those larvae feeding on a second host of trembling aspen had the highest ranked average weights

Fig. 1a-d Mean weights and RGRs of insects on the various second host species in the fourth and fifth instars. (NP= northern pin oak; $W O=$ white oak; $T A=$ trembling aspen; $B T=$ bigtooth aspen. Bars indicate standard errors. Different letters indicate mean values that are significantly different)
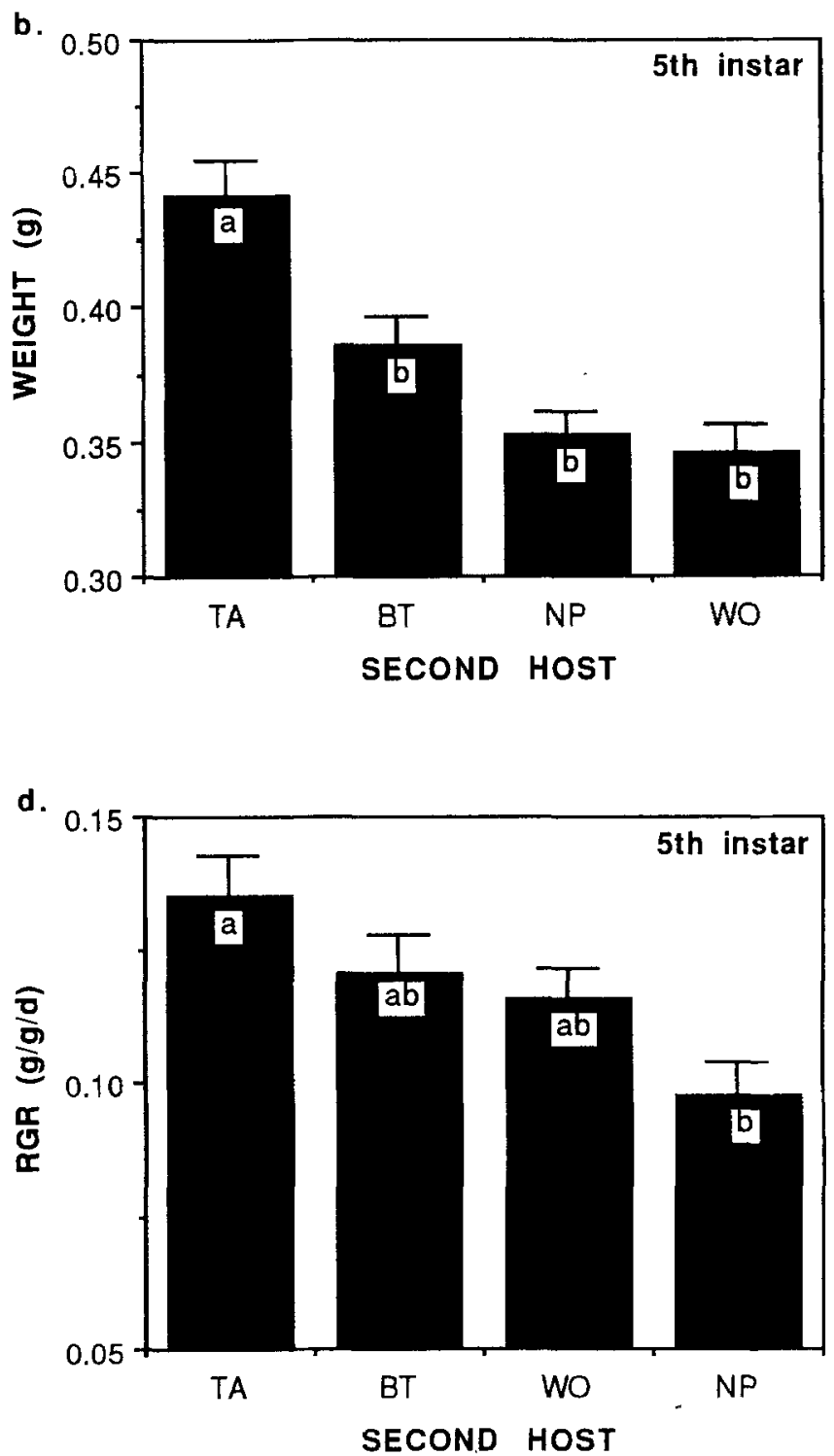
at the end of the feeding trial which took place directly after the host switch was made.

After an additional instar of feeding on the second host plant, insects on trembling aspen were not only ranked highest but were significantly ahead of insects on all other second host species in terms of mean weight (ANOVA $p=0.0001$ for second host) (Fig. 1b).

For both the fourth and fifth instar feeding trials, there was a significant interaction between first host and second host species consumed (ANOVA fourth instar $p=0.001$, fifth instar $p=0.004$ ).

\section{Relative growth rates}

Relative growth rates during the field trials in both the fourth and fifth instars show effects of second host species eaten which follow the same pattern as those seen in the weight data (ANOVA fourth instar $p=0.0014$, fifth instar $p=0.0191$ for second host) (Fig. 1c and d). During both instars, insects on a second host of trembling aspen had the highest ranked mean RGRs, and they were significantly above the average RGRs of insects on a second host of northern pin oak. Those insects feeding on either bigtooth aspen or white oak after the host switch were intermediate in terms of mean RGR and not significantly different from the species at either extreme.

The first host experience of the larvae had significant effects on RGRs attained during both of the measurement periods after the host switch took place (Fig. 2). In the field trial immediately following the host switch, insects that had come from a first host of either northern pin oak or bigtooth aspen were growing at a significantly slower average rate than insects that did their initial feeding on either trembling aspen or white oak regardless of their second host species (ANOVA $p=0.0001$ for first host) (Fig. 2a). Once larvae had spent an additional instar on their new host, however, insects which had eaten a first host of northern pin oak had the highest ranked average growth rates, significantly higher than those of larvae which had been on bigtooth aspen before the host switch (ANOVA $p=0.0016$ for first host) (Fig. 2b). Larvae which did their initial feeding on white oak or trembling aspen were intermediate in terms of mean growth rates during the fifth instar.

For both instars, there were significant interactions between first and second host species (ANOVA fourth instar $p=0.0001$, fifth instar $p=0.023$ ).

\section{Food consumption}

Dry consumption rates (grams of dry food consumed per larva per day) across host species were an average of 1.9 times higher during the fifth instar than during the fourth instar. Consumption increases ranged from a 2.5 fold average increase in dry weight of leaf material consumed for insects on a second host of bigtooth aspen to a 1.5 fold mean increase on a second host of northern
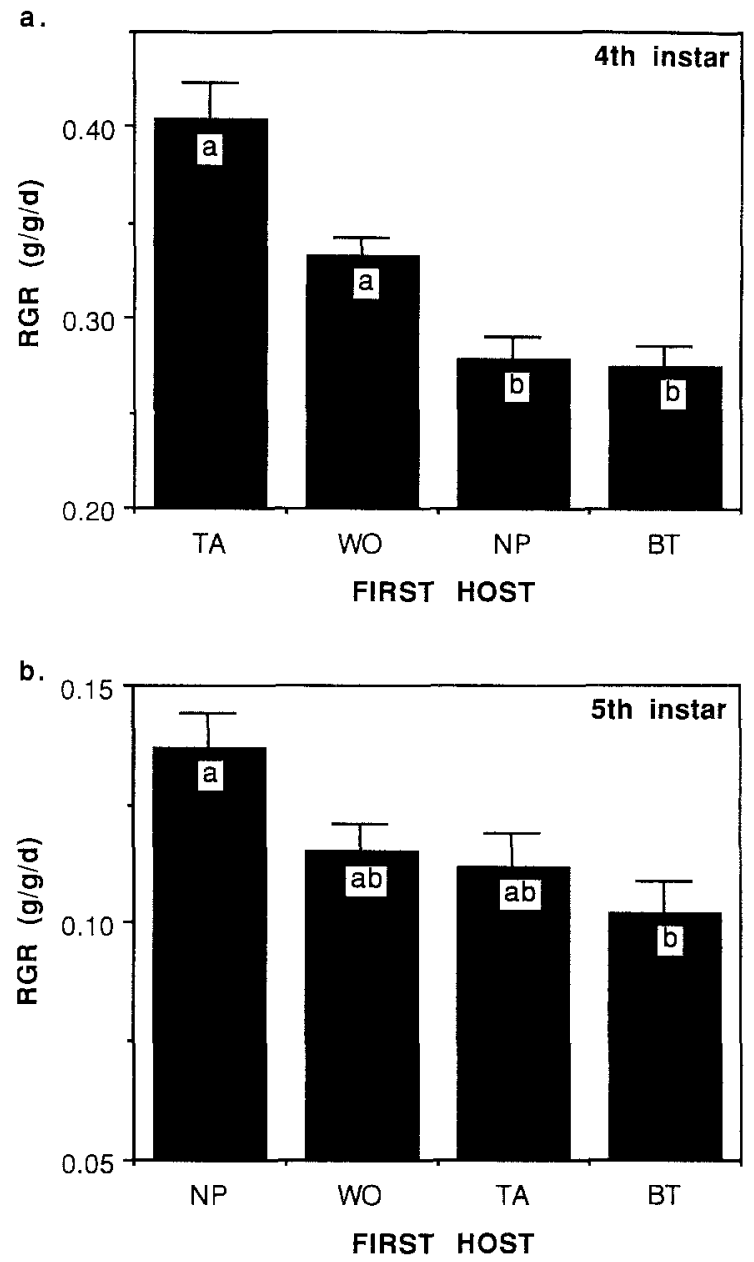

Fig. 2a, b Mean RGRs during the fourth and fifth instars for insects that had experienced different initial host species. $(N P=$ northern pin oak; $W O=$ white oak; $T A=$ trembling aspen; $B T=$ bigtooth aspen. Bars indicate standard errors. Different letters indicate mean values that are significantly different)

pin oak (fourth instar: trembling aspen $=0.039 \pm 0.002$ $\mathrm{g} / \mathrm{d}$, northern pin oak $=0.036 \pm 0.001 \mathrm{~g} / \mathrm{d}$, white oak $=0.032 \pm 0.001 \mathrm{~g} / \mathrm{d}$, bigtooth aspen $=0.028 \pm 0.001$ $\mathrm{g} / \mathrm{d}$; fifth instar: trembling aspen $=0.084 \pm 0.004 \mathrm{~g} / \mathrm{d}$, bigtooth aspen $=0.071 \pm 0.003 \mathrm{~g} / \mathrm{d}$, white $0 a k=$ $0.053 \pm 0.002 \mathrm{~g} / \mathrm{d}$, northern pin oak $=0.053 \pm 0.002 \mathrm{~g} / \mathrm{d}$ ). Wet weight consumption across all species increased an average of 1.7 times between the fourth and fifth instars, ranging from a 2.1 fold increase on bigtooth aspen to a 1.3 fold increase on northern pin oak (fourth instar: trembling aspen $=0.098 \pm 0.006 \mathrm{~g} / \mathrm{d}$, northern pin oak $=0.091 \pm 0.003 \mathrm{~g} / \mathrm{d}$, white oak $=0.084 \pm 0.003 \mathrm{~g} / \mathrm{d}$, bigtooth aspen $=0.069 \pm 0.002 \mathrm{~g} / \mathrm{d}$; fifth instar: trembling aspen $=0.185 \pm 0.009 \mathrm{~g} / \mathrm{d}$, bigtooth aspen $=$ $0.148 \pm 0.007 \mathrm{~g} / \mathrm{d}$, white oak $=0.122 \pm 0.006 \mathrm{~g} / \mathrm{d}$, northern pin oak $=0.118 \pm 0.005 \mathrm{~g} / \mathrm{d}$ ).

Relative consumption rates on wet and dry food bases were strongly affected both by the species being consumed after the host switch and by the species on which larvae had their early feeding experience. Immediately after the host switch took place, insects which 

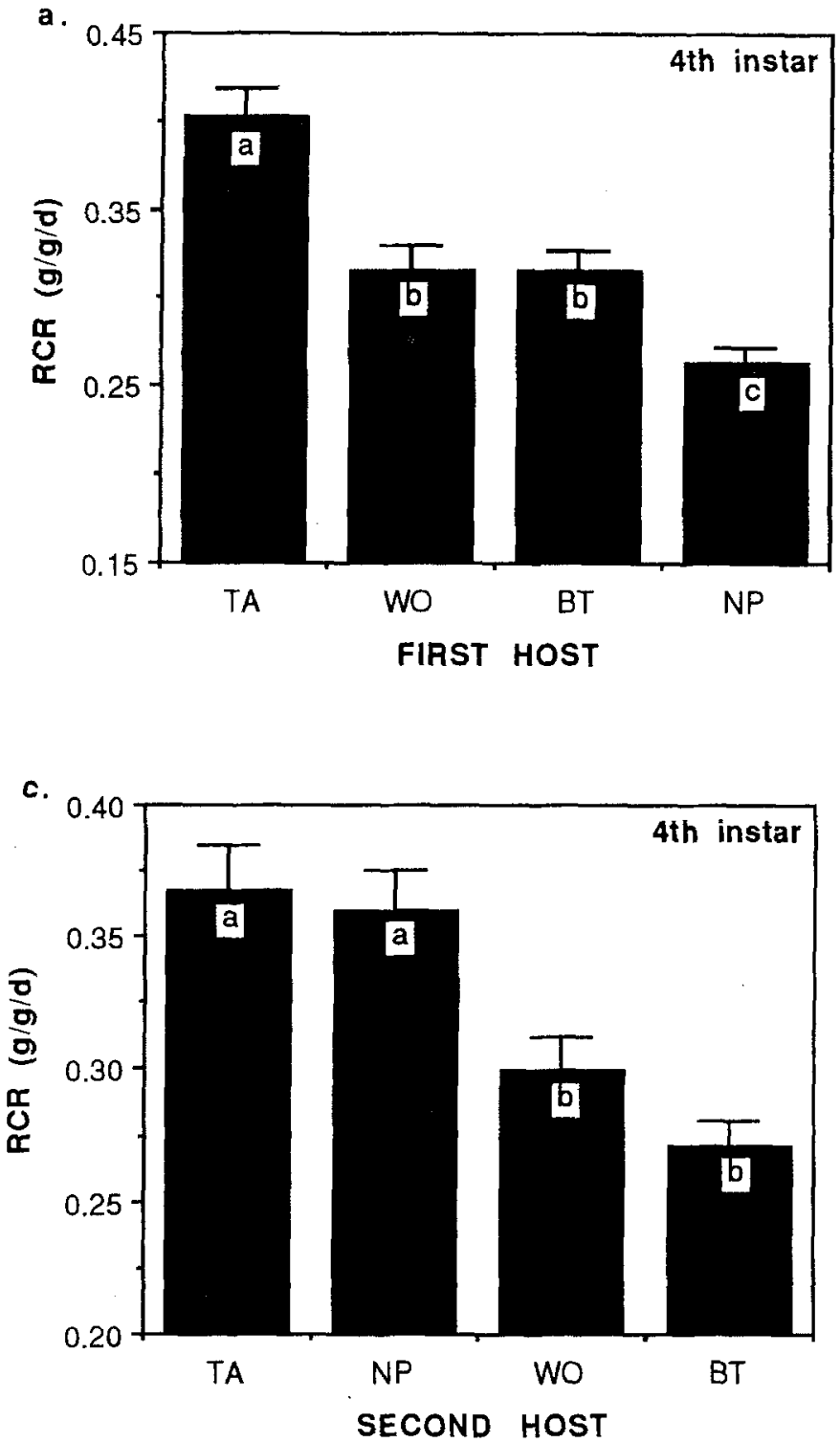

Fig. 3a-d Mean RCRs on a dry food basis in the fourth and fifth instars for insects that experienced different first and second host species. $(N P=$ northern pin oak; $W O=$ white oak; $T A=$ trembling aspen; $B T=$ bigtooth aspen. Bars indicate standard errors. Different letters indicate mean values that are significantly different)

had come from a first host of trembling aspen were consuming significantly higher average amounts on both a wet and dry food basis than insects from any other first host species (dry food basis: Fig. 3a; wet food basis: trembling aspen $=1.01 \pm 0.04 \mathrm{~g} / \mathrm{g} / \mathrm{d}$, white oak $=$ $0.79+0.04 \mathrm{~g} / \mathrm{g} / \mathrm{d}$, bigtooth aspen $=0.79 \pm 0.03 \mathrm{~g} / \mathrm{g} / \mathrm{d}$, northern pin oak $=0.66 \pm 0.02 \mathrm{~g} / \mathrm{g} / \mathrm{d} ;$ ANOVA both wet and dry food bases $p=0.0001$ for first host). Those from a first host of northern pin oak were consuming significantly less than all others immediately after the host switch, while those from first hosts of either white oak or bigtooth aspen were intermediate in RCRs and significantly different from both trembling aspen-started and northern pin oak-started insects. One instar later, how-
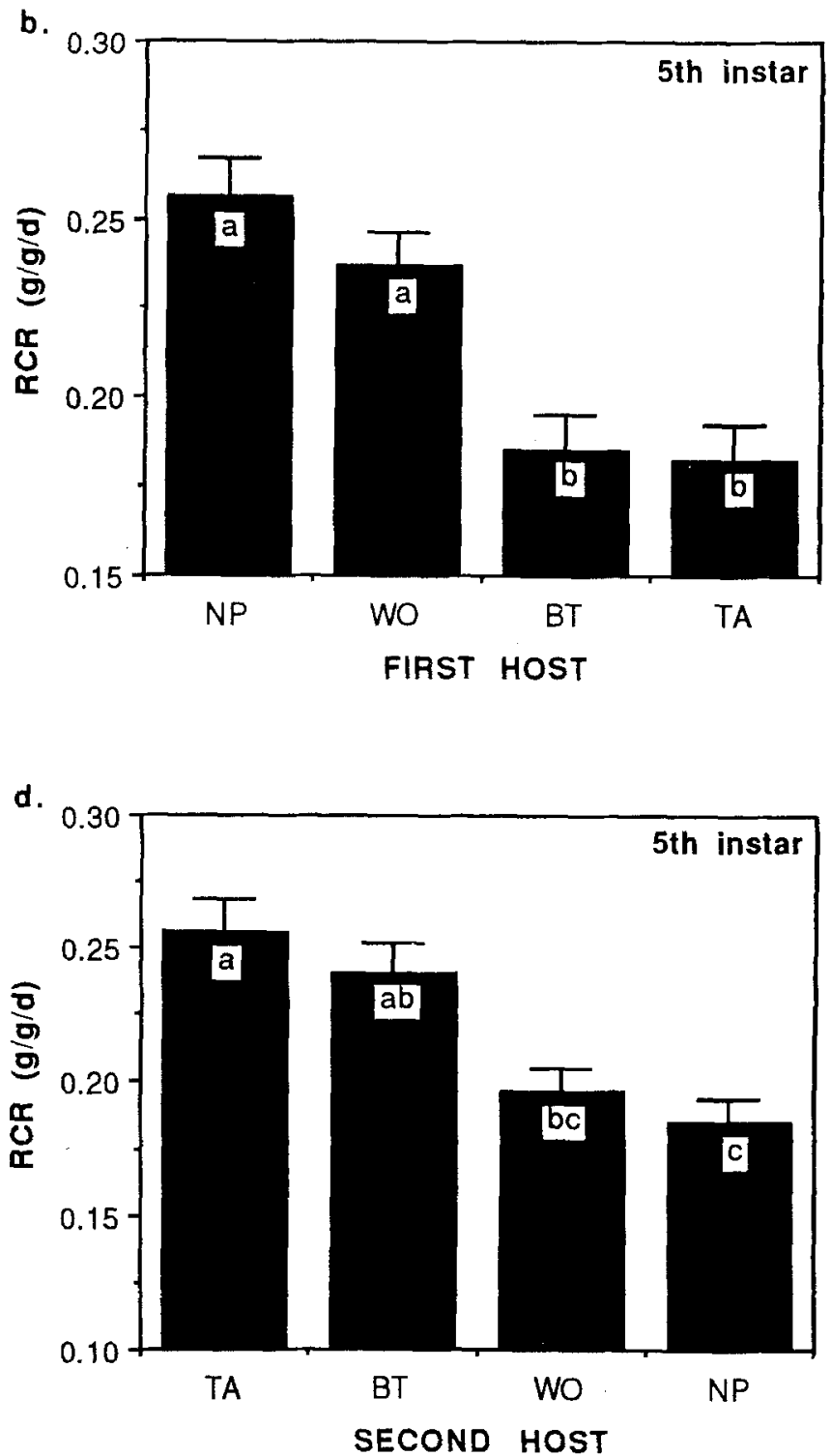

ever, insects which had either oak species as a first host were consuming significantly more on average relative to their body weight on both wet and dry food bases than were insects which had done their initial feeding on either aspen species (dry food basis: Fig. 3b; wet food basis: northern pin oak $=0.56 \pm 0.02 \mathrm{~g} / \mathrm{g} / \mathrm{d}$, white oak $=0.52 \pm 0.02 \mathrm{~g} / \mathrm{g} / \mathrm{d}$, bigtooth aspen $=0.41 \pm 0.02 \mathrm{~g} /$ $\mathrm{g} / \mathrm{d}$, trembling aspen $=0.40 \pm 0.02 \mathrm{~g} / \mathrm{g} / \mathrm{d} ;$ ANOVA both wet and dry food bases $p=0.0001$ for first host).

Directly after the host switch, insects on a second host of either trembling aspen or northern pin oak had the highest average dry food RCRs and were significantly higher in terms of this variable than insects on either white oak or bigtooth aspen (ANOVA $p=0.0001$ for second host) (Fig. 3c). Likewise on a wet food basis, insects on a second host of either trembling aspen $(0.92 \pm 0.04 \mathrm{~g} / \mathrm{g} / \mathrm{d})$ or northern pin oak $(0.90 \pm 0.04 \mathrm{~g} / \mathrm{g}$ d) consumed the most on average, followed by insects on white oak $(0.79 \pm 0.03 \mathrm{~g} / \mathrm{g} / \mathrm{d})$, with insects on a second host of bigtooth aspen $(0.66 \pm 0.02 \mathrm{~g} / \mathrm{g} / \mathrm{d})$ consuming sig- 
a.

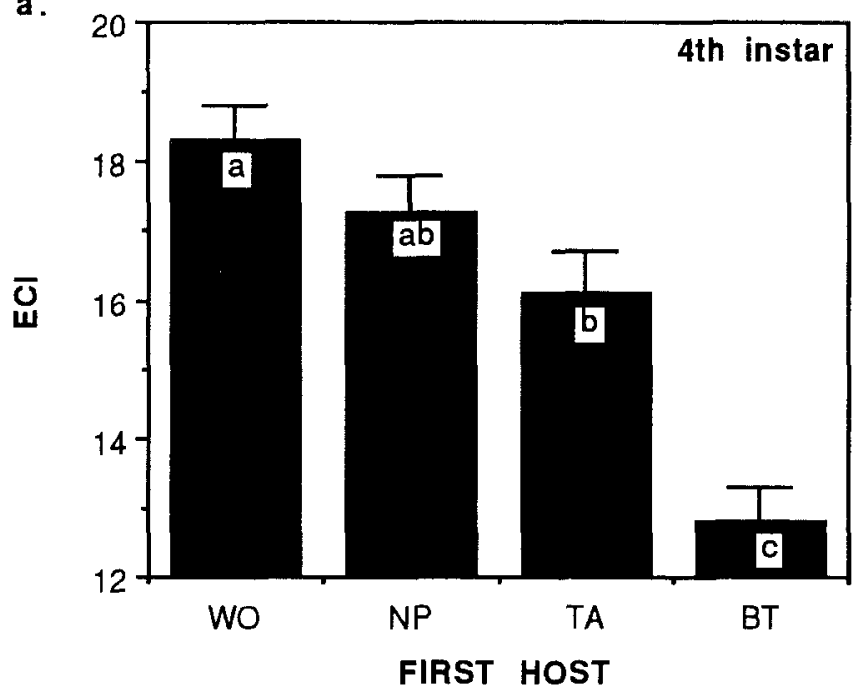

c.

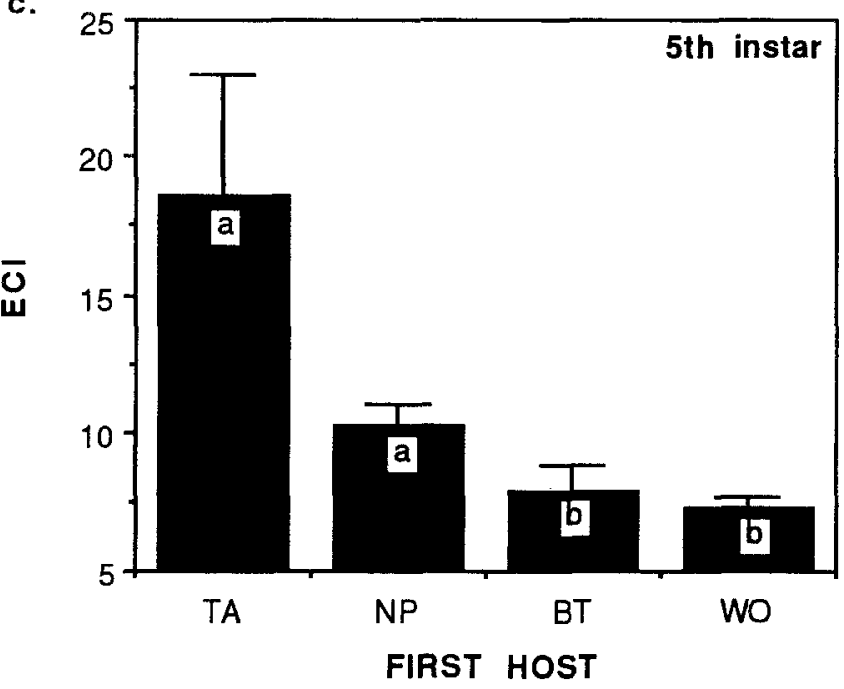

nificantly less than insects on any other second host species (ANOVA $p=0.0001$ for second host).

After an additional instar of experience on the second host plant, however, insects on both aspen species were consuming relatively more on average on both wet and dry food bases and were now significantly ahead of insects which had been placed on a second host of northern pin oak (dry food basis: Fig. 3d; wet food basis: trembling aspen $=0.56 \pm 0.03 \mathrm{~g} / \mathrm{g} / \mathrm{d}$, bigtooth aspen $=0.50 \pm 0.02 \mathrm{~g} / \mathrm{g} / \mathrm{d}$, white oak $=0.46 \pm 0.02 \mathrm{~g} / \mathrm{g} / \mathrm{d}$, northern pin oak $=0.41 \pm 0.02 \mathrm{~g} / \mathrm{g} / \mathrm{d} ;$ ANOVA both wet and dry food bases $p=0.0001$ for second host). Insects on trembling aspen also had significantly higher mean relative wet and dry consumption rates than insects on a second host of white oak, although bigtooth aspen-fed insects were not significantly different in terms of this variable from the white oak-fed insects (Fig. 3d).

There were significant interactions between first and second hosts consumed for both wet and dry relative consumption rates during both instars (ANOVA wet
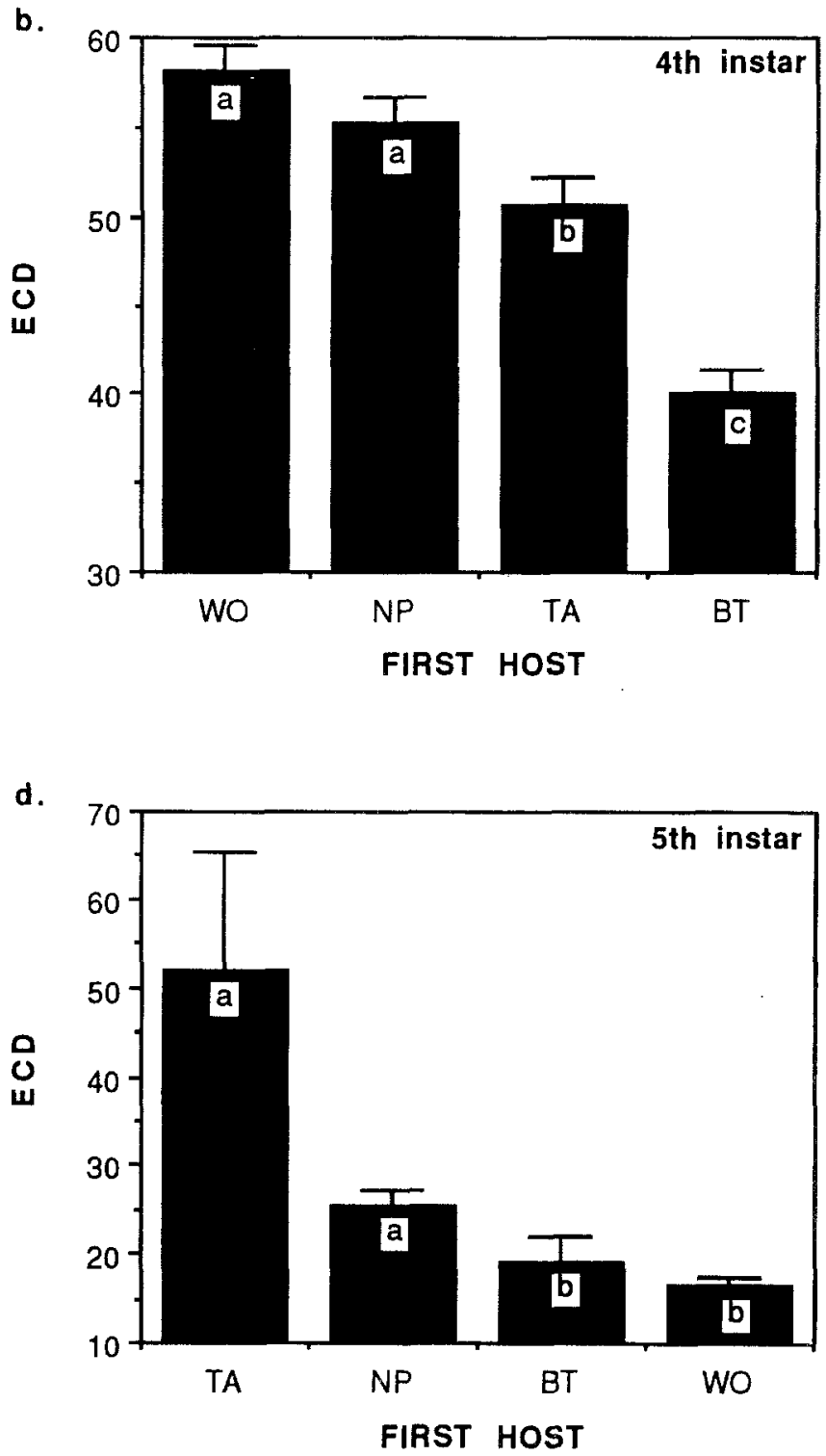

Fig. 4a-d Mean ECIs and ECDs in the fourth and fifth instars for insects that experienced different first host species. $(N P=$ northern pin oak; $W O=$ white oak; $T A=$ trembling aspen; $B T=$ bigtooth aspen. Bars indicate standard errors. Different letters indicate mean values that are significantly different)

food basis: fourth instar $p=0.0001$, fifth instar $p=0.007$; dry food basis: fourth instar $p=0.0001$, fifth instar $p=0.006$ ).

\section{Efficiency of food utilization}

Immediately after the host switch, those insects which had feeding experience as young larvae before the host switch on either white oak or northern pin oak were utilizing both their ingested and digested second host foods the most efficiently of all the insects to build body mass (Fig. 4a and b). Mean ECI of insects from a first host of white oak was significantly higher than that of 

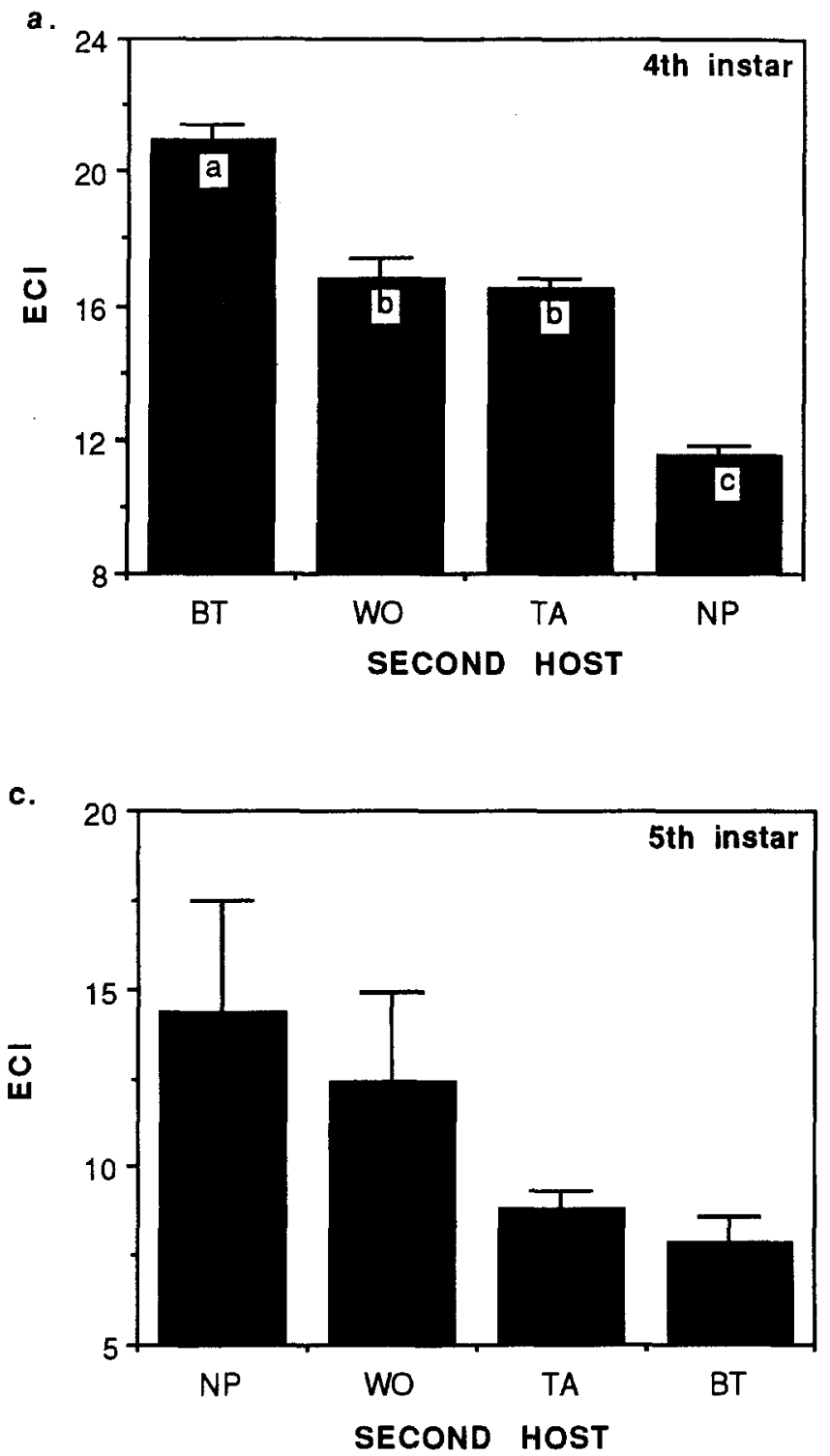

insects from either aspen species, while insects with an early diet of northern pin oak were significantly ahead of insects from bigtooth aspen (ANOVA $p=0.0001$ for first host) (Fig. 4a). Mean ECDs of insects from both oak species were significantly higher than those for insects from either aspen species (ANOVA $p=0.0001$ for first host) (Fig. 4b). In terms of both mean ECI and mean ECD, insects which had feeding experience before the switch on bigtooth aspen were performing significantly more poorly in terms of food utilization efficiency immediately after a host switch than all other insects (Fig. $4 \mathrm{a}$ and $\mathrm{b}$ ).

After an additional instar was spent on the second host plant, insects which had feeding experience before the host switch on either trembling aspen or northern pin oak were able to utilize their second host plants significantly more efficiently on average than other insects, having significantly higher ECIs (ANOVA $p=0.0001$ for first host) and ECDs (ANOVA $p=0.0001$ for first host) than insects whose first
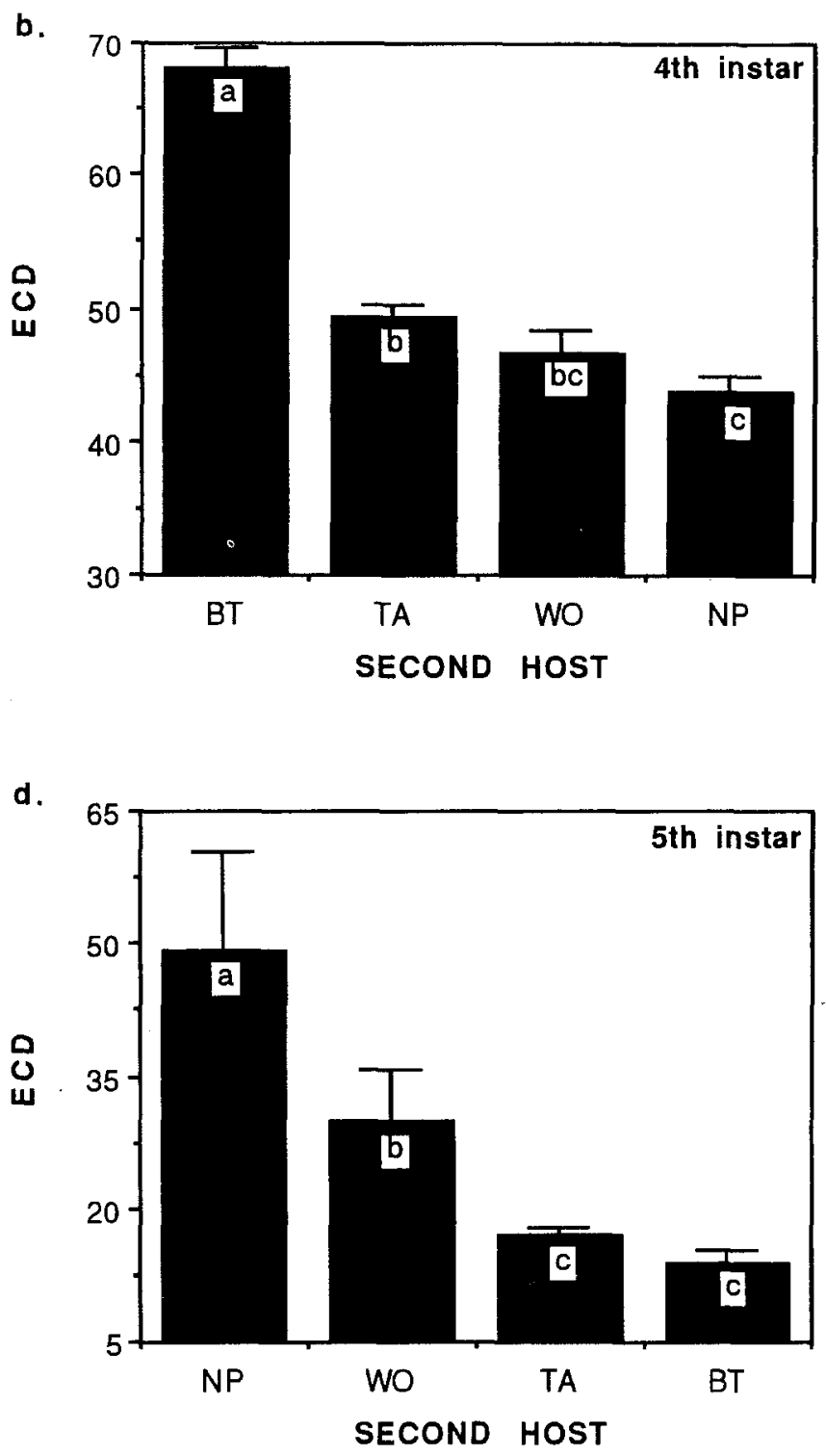

Fig. 5a-d Mean ECIs and ECDs in the fourth and fifth instars for insects that experienced different second host species. (NP= northern pin oak, $W O=$ white oak; $T A=$ trembling aspen; $B T=$ bigtooth aspen. Bars indicate standard errors. Different letters indicate mean values that are significantly different)

hosts had been either white oak or bigtooth aspen (Fig. $4 \mathrm{c}$ and $\mathrm{d}$ ).

While insects coming from a first host of bigtooth aspen did not perform well in terms of efficiency after switching to new host plants, insects that were placed onto a second host of bigtooth aspen from the various first host species benefitted immediately after the host switch. When we examined insects from all first host species that moved to a second host of bigtooth aspen we found that they had significantly higher ECIs (ANOVA $p=0.0001$ for second host) and ECDs (ANOVA $p=0.0001$ for second host) on average than insects on any other second host species in the fourth instar (Fig. 5a and b). Insects on a second host of north- 
ern pin oak had the lowest ranked utilization efficiency in the $3 \mathrm{~d}$ period immediately after the host switch, being significantly lower in terms of mean ECI than all other insects and significantly lower in terms of mean ECD than all insects but those on white oak after the switch.

This situation was reversed once insects had been exposed to their second host species for an entire instar, however (Fig. 5c and d). In the fifth instar, insects on a second host of northern pin oak had the greatest average ECD (Fig. 4d) and were significantly ahead of all others, followed by insects on a second host of white oak, which were significantly ahead of those from either aspen species (ANOVA $p=0.0001$ for second host). While differences in mean ECIs (Fig. 4c) at this instar were not strong enough to be statistically significant, they followed the same pattern in terms of rank order as that seen for ECDs at this instar (ANOVA $p=0.061$ for second host).

There were significant interactions between first and second host species for both ECI and ECD at both instars (ANOVA $p=0.0001$ for interactions for both ECI and ECD at each instar).

Relationship of first and second host species

Significant interaction terms occurred for each variable examined in this study (values presented throughout results section). Because of these significant interactions, we needed to further explore the interrelationships between first and second host species. For each first host and variable studied, we examined mean values of the variables on the diet types that shared the same first host species. By looking at the responses for the groups of insects that were eating different second host species but had in common the same type of first host species, we could determine the pattern of interrelationships that were occurring between first and second hosts. This examination revealed no clear trends such as consumptions or efficiencies tending to be higher if the second plant species consumed was either the same species as the first plant eaten or a species congeneric to it. There were no trends apparent which differentiated between oak and aspen second hosts for either oak or aspen first hosts. Rather, performance patterns seen within each of the subgroups of diets tended to mirror the general first host and second host effects described in the earlier sections for each variable, with some small variations present that caused significance in the interaction terms but did not form clear, meaningful patterns.

\section{Discussion}

All phytophagous insects, even those that are highly specialized, are likely exposed to some variability in the nutritional quality and chemistry of their food material (Scriber and Slansky 1981). The level of variation expe- rienced in the diet is greatest for polyphagous individuals, however, whose success depends upon their ability to utilize multiple host species. Stoyenoff et al. (1994) studied gypsy moth performance in the field on a variety of single and two species diets and found that differences in growth and survival occurred for this insect even among diet sequences composed of two favorable host species. In those experiments, insects that fed on a first host of red oak had the highest levels of performance before the host switch and continued to have higher larval weights and faster development than insects from other first host species after being switched to various second host plants. In the present study, we found that northern pin oak had the same type of beneficial effects as a first host plant for gypsy moth larvae that red oak had shown in our earlier work. This is not surprising since Chilcote (1990) has demonstrated that northern pin oak is generally comparable to, or better than, red oak as a host for gypsy moths. The best second host species for larvae to switch onto, in terms of insect performance, was trembling aspen. This was true both in our previous work (Stoyenoff et al. 1994) and in the current study. Likewise, Roden and Surgeoner (1991) found that diet combinations that included trembling aspen led to faster development and heavier pupae.

The life-long benefits that accrue to gypsy moths from feeding on a first host of northern pin oak appear to be due to a combination of high food consumption and relatively efficient use of ingested and digested food after a host switch. While insects which did their initial feeding on northern pin oak had very low consumption rates in the $3 \mathrm{~d}$ immediately following a switch to a new host species, one instar later they show top-ranked rates in terms of both food consumption and insect growth. The insects that ate oaks as their first hosts were more efficient immediately after a host switch at converting both ingested and digested food to body mass. One instar later, insects that had done their initial feeding on northern pin oak were still ranked second highest in terms of efficiency and were not significantly different from the most efficient group of insects, those which had eaten trembling aspen as their first host plant.

Highly efficient food use is not always a requirement for good growth, however. The most beneficial second host species for gypsy moth was trembling aspen. Despite the excellent growth which occurs on aspen after the host switch, insects on a second host of trembling aspen are not particularly efficient at converting ingested or digested food to body mass. This lack of efficiency is offset, however, by high relative consumption rates both immediately after insects move onto this host and one instar later.

While trembling aspen was highly palatable to gypsy moth larvae both immediately after insects switched onto it and also one instar later, feeding rates on other host species changed over time after the host switch occurred. For instance, northern pin oak seemed to be quite readily consumed immediately after the host switch took place, but one instar later average relative 
consumption rates of insects caged on a second host of northern pin oak were lower than average consumption rates of insects on any of the other second host species. This decrease in consumption may have been due to increased leaf toughness, increased levels of feeding deterrents in the foliage, decreased water content, or other physical and/or chemical changes which led to a decrease in phagostimulation for insects caged on this species (Scriber and Slansky 1981; Schultz and Baldwin 1982; Raupp and Denno 1983; Mattson and Scriber 1985; Slansky and Scriber 1985). It also may have been due to changes over time in the internal efficiency with which insects could utilize this host species.

High efficiency of food conversion was frequently associated with low food consumption and vice versa in this study. A similar phenomenon has been seen in numerous studies on other insects as well (Slansky and Feeny 1977; Barbosa and Greenblatt 1979; Bernays 1985; Abisgold and Simpson 1987). Soo Hoo and Fraenkel (1966), finding results of this type for Spodoptera eridania fifth instar larvae on various diets, noted that the negative correlations between RCRs and efficiencies could have either of two explanations. First, when larvae consume less, the food will tend to pass through their digestive system more slowly and thus it can be more completely converted and used by the insects. Second, it may be that insects consume less of a particular food simply because they are capable of converting it more efficiently and therefore do not need to eat large quantities of that food in order to obtain appropriate levels of growth. It is likely that neither explanation is valid to the exclusion of the other. Rather, both are probably important in helping us to understand insect feeding responses seen in past research and in the currently reported results. It should be noted that ECD in this experiment generally decreased between the fourth and fifth instars. While counter to the general trend of increase in ECD from early to late instars reported by Slansky and Scriber (1985), these results are in agreement with those of Stockhoff (1992) who found a similar ECD decline when examining nutritional responses of gypsy moths on artificial diet under laboratory conditions.

Many researchers studying effects of diet switches in other lepidopterans have found that prior feeding experience influences both behavioral and physiological ability to utilize subsequent host plants (Jermy et al. 1968; Hanson 1976; Schoonhoven and Meerman 1978; Scriber 1979, 1981, 1982; Grabstein and Scriber 1982; Karowe 1989). If gypsy moth larvae were strongly induced by their first host species as are many other lepidopterans, a host switch would most likely negatively affect their survival and growth, and we would expect host switching behavior to be suppressed as deleterious. However, gypsy moth larvae often may switch freely between diet items in nature (Doane and Leonard 1975; Lance and Barbosa 1982; Liebhold et al. 1986); either inductions must not strongly affect them or other consequences of host switching must be so greatly positive that they overcome any negative effects associated with inductions. Results of our study indicate that the former is the case. While first host and second host species consumed did significantly interact, we did not find any tendancy for gypsy moth larvae in this study to consume more, grow faster, or convert food more efficiently when their second host plant was either the same as their rearing plant or congeneric to it. Rather, their performance was high after a host switch if they had moved onto a "good" second host species (e.g., trembling aspen) regardless of the relationship between that species and their first host, or if they had done their early feeding on a "good" first host species (e.g., northern pin oak) regardless of its relationship to their later host plant. The lack of induction effects seen in these results is in agreement with laboratory and field research on host switching in gypsy moths indicating that sequential diets do not have negative effects per se on larvae and may in fact be highly beneficial to them (Barbosa 1978b; Barbosa et al. 1986; Roden and Surgeoner 1991; Stoyenoff et al. 1994). In fact, in these previous studies, gypsy moths frequently exhibit higher performance on a diet involving a host switch than on a continued diet of their first host plant alone.

One result from our previous research that cannot be explained by the present study was a tendency which we saw in other years for insects switched to a second host of white oak to perform better than other insects in the period immediately after the host switch, with a shift later occurring that ultimately favored insects on a second host of aspen (Stoyenoff et al. 1994). White oak was not the most beneficial species for insects immediately after the host switch in the current study. However, this difference that we observed may be due to the fact that both the insects and foliage were somewhat more mature in the current study than they were in our previous work at the time that the switch was made. This advance in ages of foliage and insects at the time of the switch may have led to bypassing the phenological window of time when white oak seems to be beneficial to the larvae (Raupp and Denno 1983).

Values of nutritional indices obtained for insects under natural field conditions in this study, while not intended for use as exact values to be compared with others' more controlled experiments on nutritional indices, do fall in ranges comparable to those generated by standard laboratory methods applied to third instar gypsy moths (Sheppard and Friedman 1990), fifth instar gypsy moths (Barbosa and Greenblatt 1979), penultimate and ultimate instar larvae of a number of tree-feeding lepidopterans studied by Scriber $(1975,1977,1979)$, and food-to-frass ratio data reviewed for a number of tropical lepidopterans by Mathavan and Pandian (1974), among other research results. The ability to perform such work directly in the field was strongly suggested by Mathavan and Pandian's (1974) finding of high correlations between frass weights and food consumptions for lepidopteran larvae. However, while a technique using lab generated food-to-frass ratios was implemented to 
determine food consumption from frass output of field collected harvestmen (Phillipson 1960) and ratios of body mass to frass production have been used as an indication of host plant foliage quality (Koricheva and Haukioja 1992), we know of no studies aside from ours which utilize such techniques to allow determination of nutritional indices for insects living under field conditions. It is hoped that the techniques presented here will encourage others to apply similar methods in their work as appropriate to better elucidate insect nutritional responses in the field.

Acknowledgements We thank G.W. Fowler for statistical consultation in this study. The work was supported by the McIntireStennis Cooperative Forestry Research Act (PL 87-188), the United States Department of Agriculture-United States Forest Service, and The University of Michigan. The Michigan Department of Natural Resources provided summer housing for research participants.

\section{References}

Abisgold JD, Simpson SJ (1987) The physiology of compensation by locusts for changes in dietary protein. J Exp Biol 129:329346

Ahmad S (1983) Mixed-function oxidase activity in a generalist herbivore in relation to its biology, food plants, and feeding history. Ecology 64:235-243

Barbosa P (1978a) Distribution of an endemic larval gypsy moth population among various tree species. Environ Entomol $7: 526-527$

Barbosa P (1978b) Host plant exploitation by the gypsy moth, Lymantria dispar. Ent Exp Appl 24:28-37

Barbosa P, Greenblatt J (1979) Suitability, digestibility and assimilation of various host plants of the gypsy moth Lymantria dispar (L.) Oecologia 43:111-119

Barbosa P, Greenblatt J, Withers W, Cranshaw W, Harrington EA (1979) Host-plant preferences and their induction in larvae of the gypsy moth, Lymantria dispar. Ent Exp Appl 26:180-188

Barbosa P, Martinat P, Waldvogel M (1986) Development, fecundity and survival of the herbivore Lymantria dispar and the number of plant species in its diet. Ecol Ent 11:1-6

Bernays EA (1985) Regulation of feeding behaviour. In: Kerkut GA, Gilbert LI (eds) Comprehensive insect physiology, biochemistry, and pharmacology, vol 4. Pergamon Press, Oxford, pp 1-32

Bernays E, Graham M (1988) On the evolution of host specificity in phytophagous arthropods. Ecology 69:886-892

Brattsten LB (1979) Biochemical defense mechanisms in herbivores against plant allelochemicals. In: Rosenthal GA, Janzen $\mathrm{DH}$ (eds) Herbivores: their interaction with secondary plant metabolites. Academic Press, New York. pp 199-270

Brattsten LB, Price SL, Gunderson CA (1980) Microsomal oxidases in the midgut and fatbody of a broadly herbivorous insect larvae, Spodoptera eridania Cramer (Noctuidae). Comp Biochem Physiol 66C: 231-237

Capinera JL, Barbosa P (1976) Dispersal of first-instar gypsy moth larvae in relation to population quality. Oecologia $26: 53-64$

Cates RG (1980) Feeding patterns of monophagous, oligophagous, and polyphagous insect herbivores: the effect of resource abundance and plant chemistry. Oecologia 46:22-31

Chauvin R (1946) Notes sur la physiologie comparé des Orthoptères. IV Le coefficient d'utilization digestive, le rythme d'excrétion et le transit intestinal. Bull Soc Entomol Fra $51: 24-29$
Chilcote CA (1990) The effects of host phenology and site interactions on the gypsy moth, Lymantria dispar (L.). PhD dissertation, University of Michigan, Ann Arbor, MI

Doane CC, Leonard DE (1975) Orientation and dispersal of latestage larvae Porthetria dispar (Lepidoptera: Lymantriidae). Can Entomol 107:1333-1338

Evans AC (1939) The utilization of food by certain lepidopterous larvae. Trans R Entomol Soc Lond 89:13-22

Farrar Jr. RR, Barbour JD, Kennedy GC (1989) Quantifying food consumption and growth in insects. Ann Entomol Soc Am $82: 593-598$

Feeny P (1976) Plant apparency and chemical defense. In: Wallace IW, Mansell RL (eds) Recent advances in phytochemistry 10. Plenum Press, New York, pp 1-40

Grabstein EM, Scriber JM (1982) Host-plant utilization by Hyalophora cecropia as affected by prior feeding experience. Ent Exp Appl 32:262-268

Greenblatt JA, Calvert WH, Barbosa P (1978) Larval feeding preferences and inducibility in the fall webworm, Hyphantria cunea. Ann Entomol Soc Am 71:605-606

Hanson FE (1976) Comparative studies on induction of food choice preferences in lepidopterous larvae. In: Jermy $\mathrm{T}$ (ed) The host plant in relation to insect behavior and reproduction. Symp Biol Hung 16:71-77

Hanson FE (1983) The behavioral and neurophysiological basis of food plant selection by lepidopterous larvae. In: Ahmad S (ed) Herbivorous insects: host-seeking behavior and mechanisms. Academic Press, New York, pp 3-23

Ishaaya I, Swirski E (1976) Trehalase, invertase and amylase activities in the black scale, Saissetia oleae and their relation to host adaptability. J Insect Physiol 22:1025-1029

Jermy T, Hanson FE, Dethier VG (1968) Induction of specific food preference in lepidopterous larvae. Ent Exp Appl 11:211-230

Karowe DN (1989) Facultative monophagy as a consequence of prior feeding experience: behavioral and physiological specialization in Colias philodice larvae. Oecologia 78:106-111

Koricheva J, Haukioja E (1992) Effects of air pollution on host plant quality, individual performance, and population density of Eriocrania miners (Lepidoptera: Eriocraniidae). Environ Entomol 21:1386-1392

Krieger RI, Feeny PP, Wilkinson CF (1971) Detoxication enzymes in the guts of caterpillars: an evolutionary answer to plant defenses? Science 172:579-581

Lance D, Barbosa P (1981) Host tree influences on the dispersal of first instar gypsy moths, Lymantria dispar (L.). Ecol Ent 6:411416

Lance D, Barbosa P (1982) Host tree influences on the dispersal of late instar gypsy moths, Lymantria dispar. Oikos 38:1-7

Leonard DE (1981) Bioecology of the gypsy moth. In: Doane CC, McManus MM (eds) The gypsy moth: research toward integrated pest management. Forest Service Tech Bull 1584, USDA, Washington, D. C., pp 8-29

Liebhold AM, Elkinton JS, Wallner WE (1986) Effect of burlap bands on between-tree movement of late-instar gypsy moth, Lymantria dispar (Lepidoptera: Lymantriidae). Environ Entomol 15:373-379

Mathavan S, Pandian TJ (1974) Use of faecal weight as an indicator of food consumption in some lepidopterans. Oecologia $15: 177-185$

Mattson WJ, Scriber JM (1985) Nutritional ecology of insect folivores of woody plants: nitrogen, water, fiber, and mineral considerations. In: Slansky F, Rodriguez JG (eds) Nutritional ecology of insects, mites, spiders and related invertebrates, Wiley, New York

Mauffette Y, Lechowicz MJ (1984) Differences in the utilization of tree species as larval hosts and pupation sites by the gypsy moth, Lymantria dispar (Lepidoptera: Lymantriidae). Can Entomol 116:685-690

ODell TM, Butt CA, Bridgeforth AW (1985) Lymantria dispar. In: Singh P, Moore RF (eds) Handbook of insect rearing, vol II. Elsevier, Amsterdam, pp 355-367 
Phillipson J (1960) The food consumption of different instars of Mitopus morio (F.) (Phalangida) under natural conditions. J Anim Ecol 29:299-307

Price PW (1975) Insect ecology. Wiley, New York

Raupp MJ, Denno RF (1983) Leaf age as a predictor of herbivore abundance. In: Denno RF, McClure MS (eds) Variable plants and herbivores in natural and managed systems. Academic Press, New York, pp 91-124

Redfearn A, Pimm SL (1988) Population variability and polyphagy in herbivorous insect communities. Ecol Monogr 58:39-55

Rhoades D, Cates R (1976) Toward a general theory of plant antiherbivore chemistry. In: Wallace J, Mansell R (eds) Biochemical interaction between plants and insects, Rec Adv Phytochem 10 Plenum Press, New York. pp 168-213

Roden DB, Surgeoner GA (1991) Survival, development time, and pupal weights of larvae of gypsy moth reared on foliage of common trees of the upper Great Lakes region. North J Appl For 8:126-128

Rossiter MC, Schultz JC, Baldwin IT (1988) Relationships among defoliation, red oak phenolics, and gypsy moth growth and reproduction. Ecology 69:267-277

SAS (1985) SAS user's guide: statistics. SAS Institute, Cary, North Carolina Schoonhoven LM, Meerman J (1978) Metabolic cost of changes in diet and neutralization of allelochemics. Ent Exp Appl 24:689-693

Schultz JC, Baldwin IT (1982) Oak leaf quality declines in response to defoliation by gypsy moth larvae. Science 217:149151

Scriber JM (1975) Comparative nutritional ecology of herbivorous insects: generalized and specialized feeding strategies in the Papilionidae and Saturniidae (Lepidoptera). PhD dissertation, Cornell University, Ithaca, NY

Scriber JM (1977) Limiting effects of low leaf-water content on the nitrogen utilization, energy budget, and larval growth of Hyalophora cecropia (Lepidoptera: Saturniidae). Oecologia 28:269-287

Scriber JM (1979) The effects of sequentially switching foodplants upon biomass and nitrogen utilization by polyphagous and stenophagous Papilio larvae. Ent Exp Appl 25:203-215
Scriber JM (1981) Sequential diets, metabolic costs, and growth of Spodoptera eridania (Lepidoptera: Noctuidae) feeding upon dill, lima bean, and cabbage. Oecologia 51:175-180

Scriber JM (1982) The behavior and nutritional physiology of southern armyworm larvae as a function of plant species consumed in earlier instars. Ent Exp Appl 31:359-369

Scriber JM, Feeny PP (1979) Growth of herbivorous caterpillars in relation to feeding specialization and growth form of their food plants. Ecology 60:829-850

Scriber JM, Slansky F (1981) The nutritional ecology of immature insects. Ann Rev Entomol 26:183-211

Sheppard CA, Friedman S (1990) Influence of host plant, foliar phenology and larval dietary history on Lymantria dispar larval nutritional indices. Ent Exp Appl 55:247-255

Slansky F, Feeny P (1977) Stabilization of the rate of nitrogen accumulation by larvae of the cabbage butterfly on wild and cultivated food plants. Ecol Monogr 47:209-228

Slansky FJ, Scriber JM (1985) Food consumption and utilization. In: Kerkut GA, Gilbert LI (eds) Comprehensive insect physiology, biochemistry and pharmacology, vol 4, Pergamon Press, NY, pp 87-163

Soo Hoo CF, Fraenkel G (1966) The consumption, digestion, and utilization of food plants by a polyphagous insect, Prodenia. eridania (Cramer). J Insect Physiol 12:711-730

Stockhoff BA (1992) Diet heterogeneity: effects on gypsy moth feeding behavior and growth. $\mathrm{PhD}$ dissertation, University of Michigan, Ann Arbor, MI

Stoyenoff JL, Witter JA, Montgomery ME, Chilcote CA (1994) Effects of host switching on gypsy moth (Lymantria dispar (L.)) under field conditions. Oecologia 97:143-157

Waldbauer GP (1968) The consumption and utilization of food by insects. Adv Insect Physiol 5:229-289

Wasserman SS (1979) Allelochemic diversity and plant apparency: evidence from the detoxification systems of caterpillars. Am Midl Nat 102:401-403

Yamamoto RT (1974) Induction of hostplant specificity in the tobacco hornworm, Manduca sexta. J Insect Physiol 20:641650

Yu SJ (1982) Induction of microsomal oxidases by host-plants in the fall armyworm, Spodoptera frugiperda (J. E. Smith). Pesticide Biochem Physiol 17:59-67 